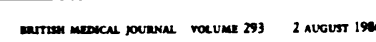
PRACTICE OBSERVED

\section{Practice Research}

Referral to medical outpatients department at teaching hospitals in Birmingham and Amsterdam

F M HULL, R F WESTERMAN

Abersect

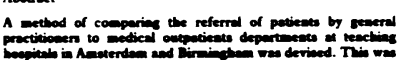

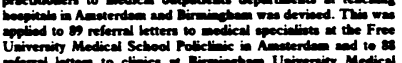

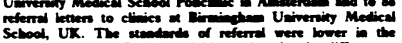

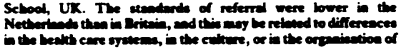

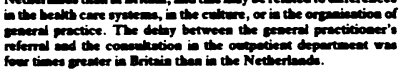

Lenterion

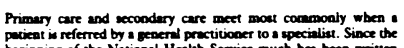

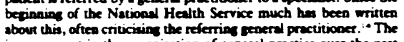

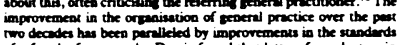

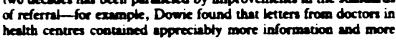

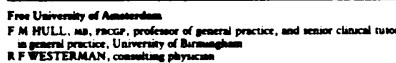

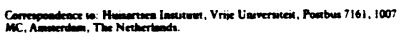
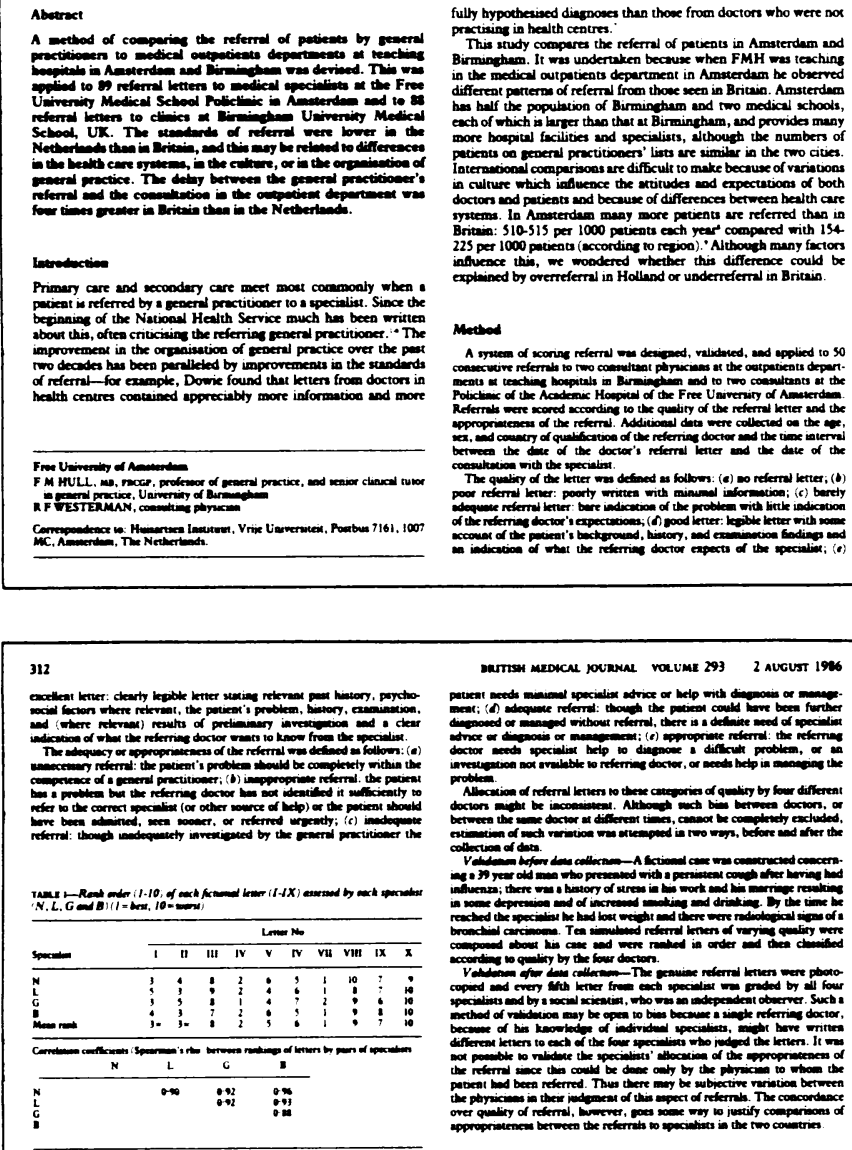

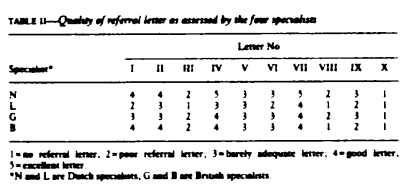
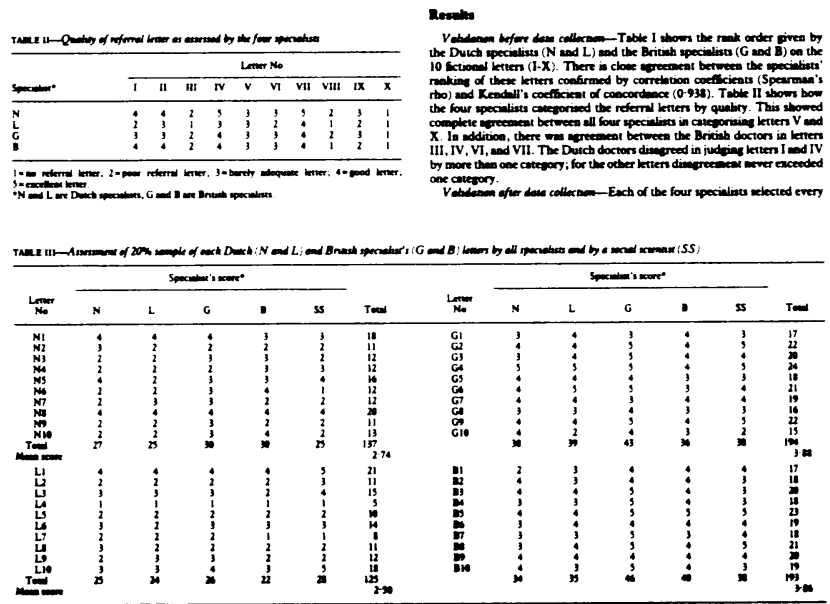

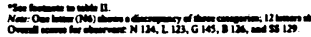

311

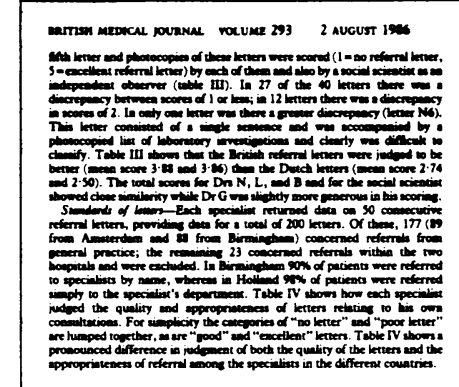

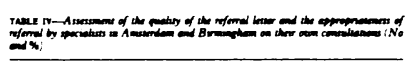

\begin{tabular}{|c|c|c|}
\hline & $\sqrt{\text { Nedt }}$ & का \\
\hline $\begin{array}{l}=1 \\
=1\end{array}$ & 华 & as \\
\hline$=$ & 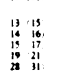 & $\begin{array}{l}3 \\
\vdots \\
\vdots \\
\vdots \\
i\end{array}$ \\
\hline test & 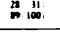 & 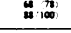 \\
\hline
\end{tabular}

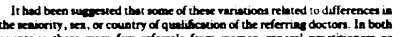

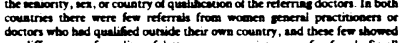

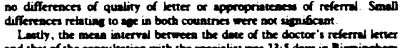

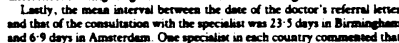

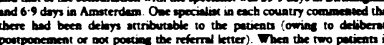

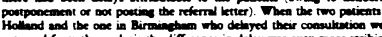

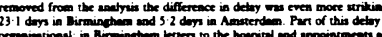

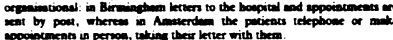

Discencioe

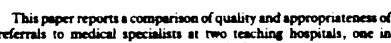

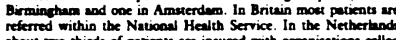

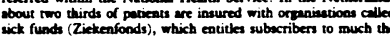

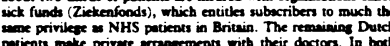

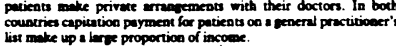

314

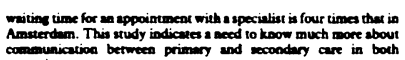

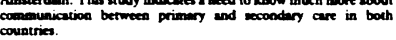

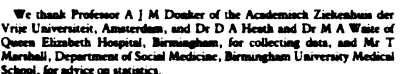
(n)

\title{
Diagnosing cancer in general practice: from suspicion to
} certainty

MAGNE NYLENNA

Anterest
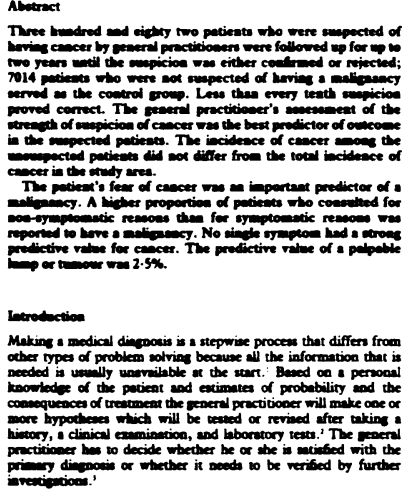

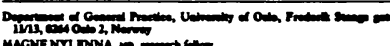

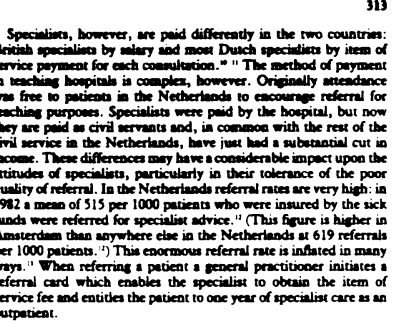

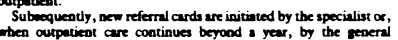

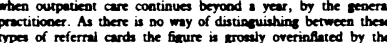

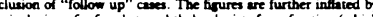

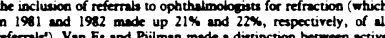

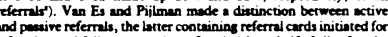

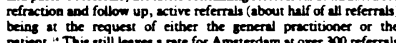

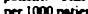

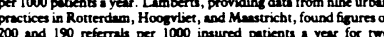

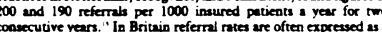

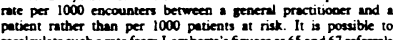

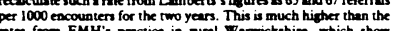

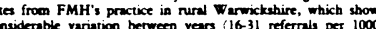

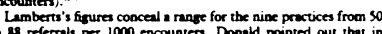

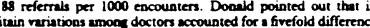

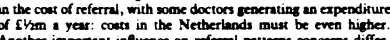

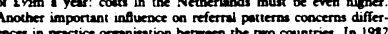

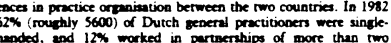

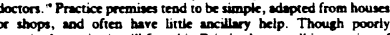

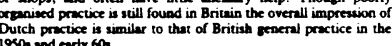

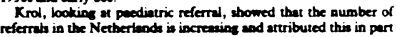

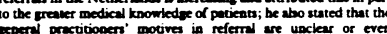

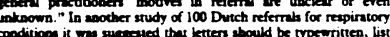

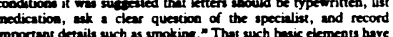

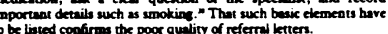

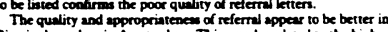

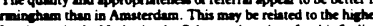

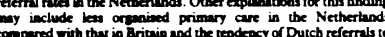

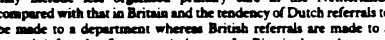

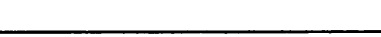

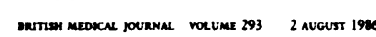

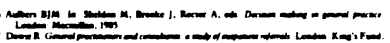
,

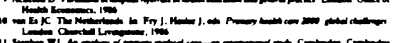
$=12=1$

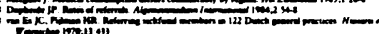
ind (n)

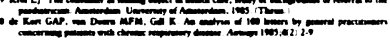
mitsons

$\underline{\underline{q}}$

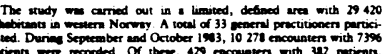
$=0$ and is $=\alpha x=m-1=0$ $=-2=-1=1$ $=1$ rem $=2=$ 

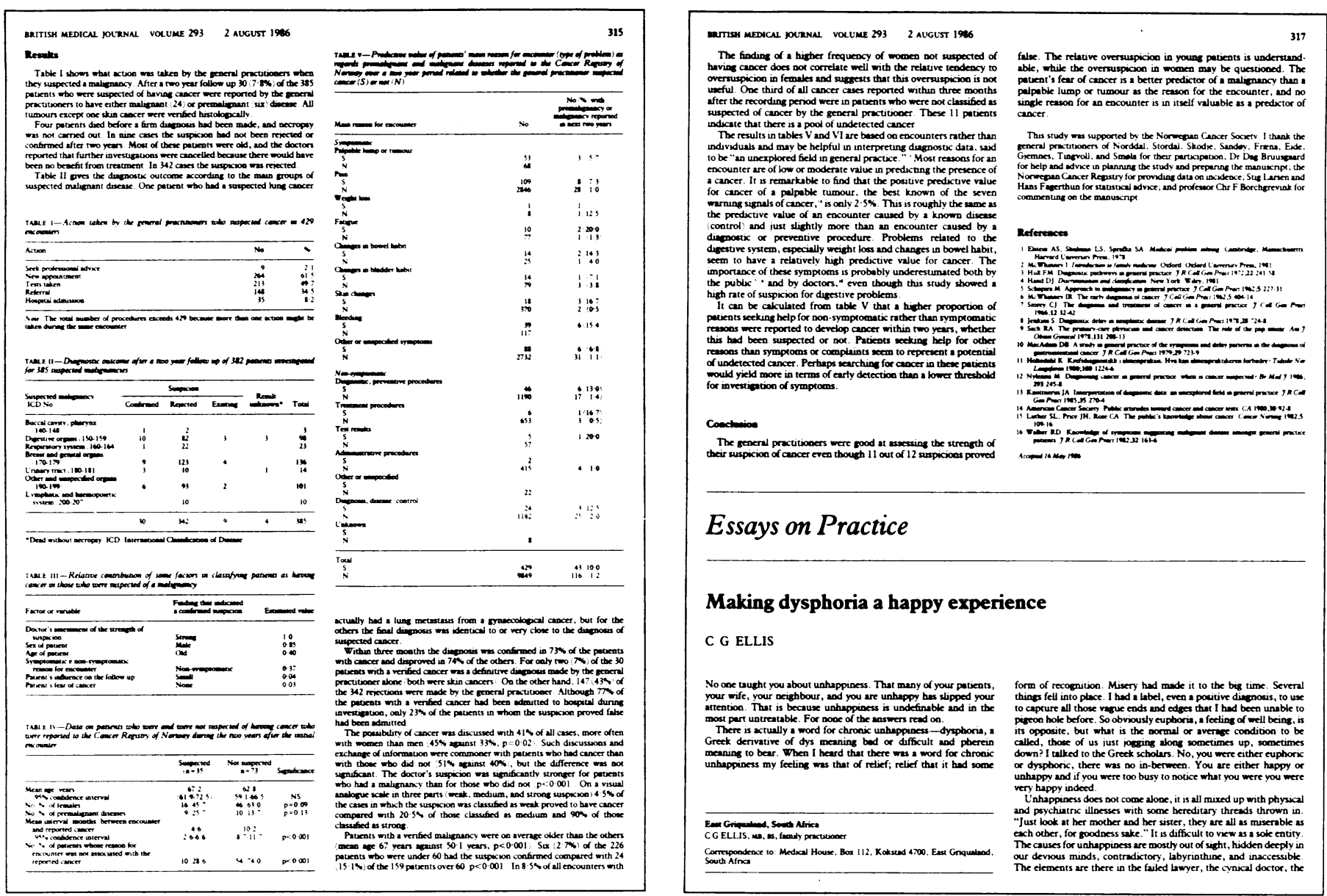

\section{Essays on Practice}

\section{Making dysphoria a happy experience}

C G ELLIS

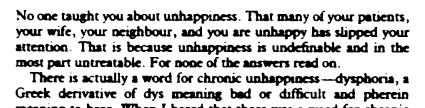

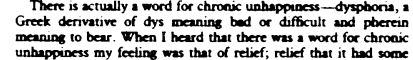

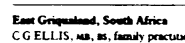

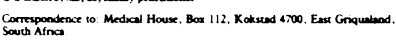
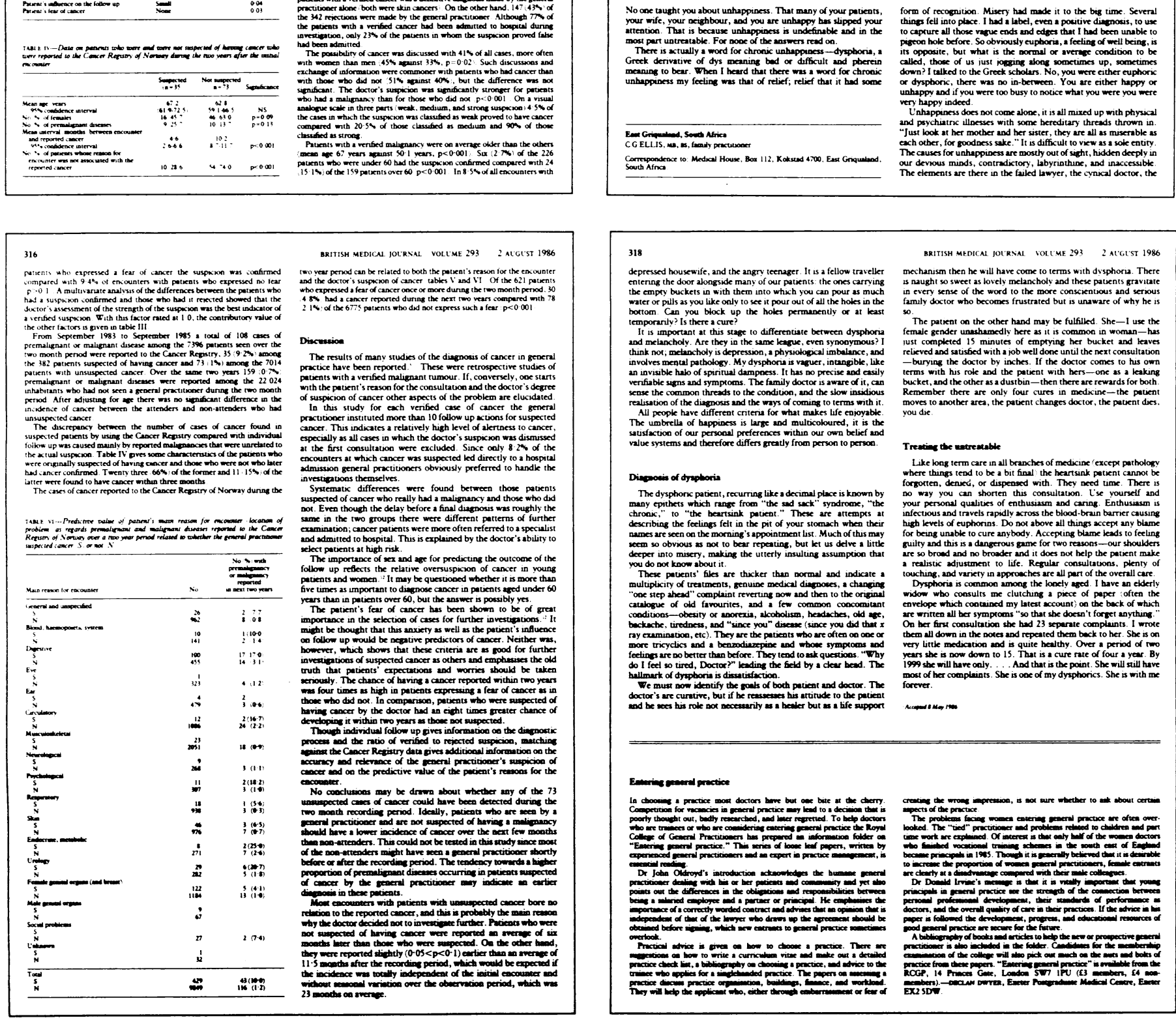

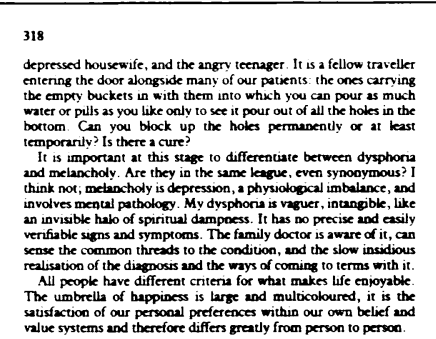

Diemeresis of oreptoris

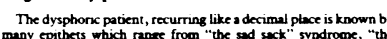

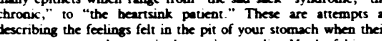

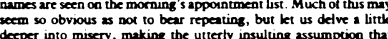

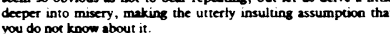

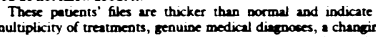

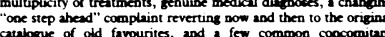

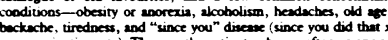

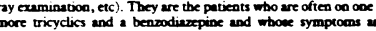

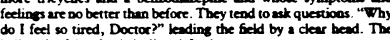

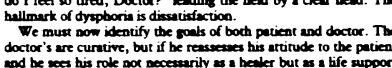

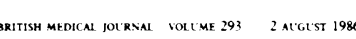

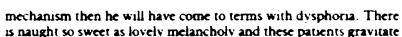

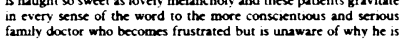
The patent on the ether hand may be fulfilited. She -1 ux the

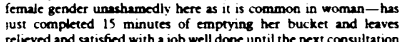

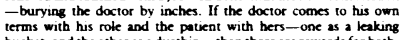

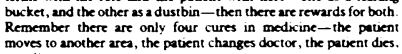

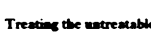

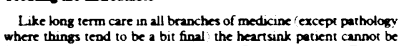

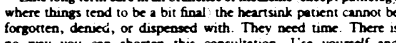

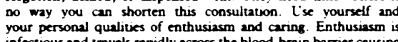

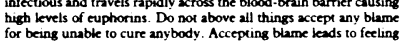

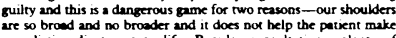

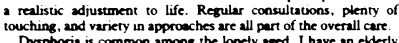

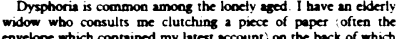

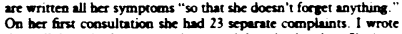

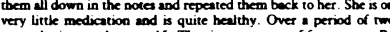

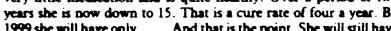

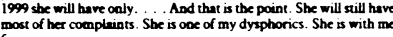
(x-minam
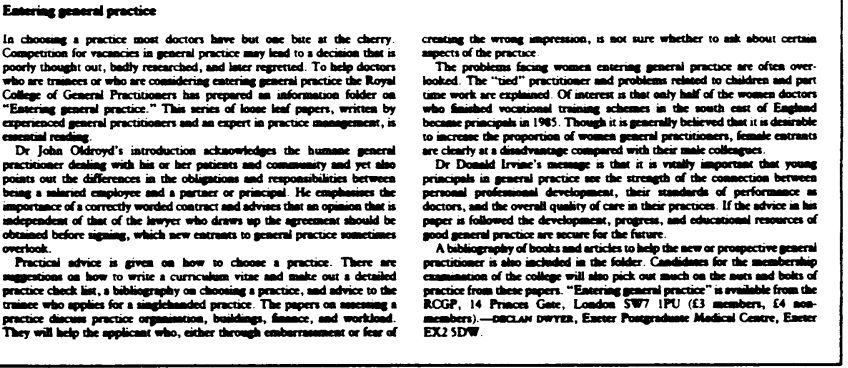